\title{
Aprendo Enseñando: Autonomy, Creativity, and Technology to Promote Mathematical Learning
}

\section{Bernal Pedraza, Oscar F.}

${ }^{a}$ Departmento de Matemáticas, Universidad de los Andes, Colombia.

\begin{abstract}
This article shortly describes some of the basic characteristics, the theoretical support, and the general framework behind an activity developed for Precalculus students named "Aprendo enseñando" (translates I Learn by Teaching), a semester-long task proposed to students aiming to elicit higher retention and deeper understanding of the mathematical procedures involved in solving the problem sets assigned for each class. The activity is brought to students as the opportunity to combine their mathematical training in class and their autonomous choices for means to present fully explained solutions to peers, involving creativity in the use of the means and technology as a requirement for the final product to be shareable over the internet. Basic examples to explore different choices were provided, periodic submissions were required, and to enhance engagement, peer review via Blackboard (Learning Management System) forums was in place. No analysis of outcomes has been conducted yet, but a retrospective view and self-critique from the teacher's point of view is provided.
\end{abstract}

Keywords: Mathematical understanding; communicating mathematics; student decision-making. 


\section{Introduction}

Brownell (1947) supported the use of meaningful or significant instruction in arithmetic for students, highlighting benefits such as increase in learning and retention, and improvements in their ability to avoid mistakes by perceiving them as anomalies. Almost thirty years later, Skemp (1976) spoke about the dual meaning of understanding in mathematics, contrasting on one side the purely algorithmic or, in his terms, instrumental mathematics taught by some teachers, and on the other side the relational mathematics, those built as a mind structure, logical and interconnected. It is not hard to see the correspondence-though not equivalence - between the meaningful learning of arithmetic and the relational mathematics; the same correspondence applies to their opposites, instrumental mathematics and meaningless arithmetic.

A clear picture of the way students are taught instrumentally is shown by Simon and Blume (1994) and Simon (1995) in reference to a teaching experiment where school teachers were the students and in their explanations they used memoristic arguments to support claims about area of rectangles. It is fair to expect for the students of those teachers to be taught exactly that way, to use memoristic arguments in support of their own mathematical claims; as their knowledge on the subject is built with the support of teachers not reaching understandings beyond those of repeating the formulas in a book, students will probably find it hard to go beyond those same formulas.

One of the main questions faced by an undergraduate-level mathematics professor is how to reach understanding when mathematics are presented in an instrumental way to students, especially in those courses where students are expected to already have the concepts and to be just warming up for more demanding subjects in their foreseeable learning path. It is not uncommon for such courses to have objectives related to meaningful learning and deep understanding, but those objectives are beyond the reach of the textbooks when the emphasis is placed on procedural fluency acquired by repetition. This is the case of the Precalculus courses using the activity described in this article, Aprendo Enseñando (AE for shortness), where the proposed activity is used as a way to elicit higher order learning in students. 


\section{The proposed activity - Aprendo Enseñando}

AE was introduced at the beginning of the second semester of year 2016 (August November) to the students of two Precalculus groups in one private university in Bogotá, Colombia. These students undertake Precalculus as a remedial course, understanding remedial as required for students failing to achieve passing scores on mathematics in at least one of two separate tests: first, before university application, the National Higher Education Access Test (known in Colombia as SABER 11); and after being accepted by the University the Mathematics Diagnostic Test, required by the university to those students not able to pass the requisite via their mathematics score in SABER 11.

There were 60 students (two groups of 30) at the beginning of the semester, one of them in Mathematics, two in other Sciences, twenty four in different branches of Engineering, and the others from other majors such as Economics, Business Administration, Law, Political Science, and Anthropology, just to mention some of them. Although those declared majors are to be seen just as descriptive data and not the basis for analysis-because it is not uncommon for students to register in a less entry-demanding major to transfer a few semesters later-it is important to have an idea of the expected need the students are going to have for further mathematics courses. These students faced the following challenge:

Given the day-by-day detailed schedule of the class, the topics and problems to be covered during each session, assemble groups from two to four students and choose weekly-on Friday-one of the problems reviewed during the week. This problem must be solved and carefully explained, and the solution and explanation must be presented in a format shareable via Internet and in a way that goes beyond still pictures and page scans.

Students were therefore required to assembly the groups and to choose the problem they were willing to attempt for the week, including autonomous decisions in the process; complete a solution for the problem, showing procedural fluency; add a full explanation for the procedure, involving some understanding and verbalization of the procedures required for the solution; and to share those pieces over the Internet using appealing formats, calling for the creativity and the use of technology.

Outcomes of the challenge were to be delivered to the teacher through the Learning Management System used by the institution, a rendition of standard Blackboard platform. A few times over the semester students were also expected to share over a forum just for their classmates and teacher, with the goal to get comments from peers and the teacher and for those comments to be available as a tool for everyone's learning. 


\subsection{Changes made for second use of the activity}

After the first semester experience, the activity was set again as part of the grade for students enrolled in two Precalculus courses during the frst academic semester of 2017 (January - May). Though some of the motivations will be discussed in deep in relevant places of the following sections of the paper, mentions of the most compelling arguments towards the changes are made here too.

Lack of feedback was one of the problems during the first semester of the activity, as the teacher's reflection shows. To address the issue, the first core change was the periodicity of the submissions. For the first semester submissions were expected weekly, but that was highly demanding both for students and for the teacher to grade. Opportunities for detailed feedback increased by spacing the submissions, from 15 total expected for the semester the number was dropped to 4 , one before each of the quarter-term tests planned for the course. In that sense, as the academic term is about four months long, the new schedule fits the findings by Kuo and Simon (2009) keeping the idea of multiple assessments and adding stronger feedback.

Also in the search for better feedback opportunities, for the second semester of the trial run all submissions were to be made on the forum, open for classmates. As classmates were able to watch their peers' proposals and to learn from their submissions, they were also expected to provide feedback on, at least, two submissions other than their own. In the words of McKeachie and Svinicki (2013), "Providing feedback is more important than assigning a grade" (p. 83) and this move from closed to open submissions to the forums, increases the feedback received by the students on their submissions. Also, making submissions part of the study materials available for the class increases the bond between $\mathrm{AE}$ and the class as a community, appealing to the idea of relatedness as a driver for motivation, as theorized by Ryan and Deci (2000).

Another change was the hiring of a Teaching Assistant with the single task to provide help to students for the Aprendo Enseñando activity whenever they asked for it, and to comment on the submissions posted in the forums. The Teaching Assistant has no grade responsibility, the only goal of hiring one is to increase the amount and quality of the feedback received by students.

Finally, as the number of submissions was drastically reduced, the size of the groups was also reduced to increase students' participation in the different aspects of the activity. For the first semester groups of four students were both allowed and encouraged, with the aim to reduce the weekly workload, but for the second semester groups were restricted to two or three students hoping to get every student to actively work in each of the four submissions. 


\section{Theoretical Support}

There are several theoretical reasons for the teacher to use this strategy to elicit understanding in students. A basic approach is based on Anderson's taxonomies for educational objectives, a revision of Bloom's taxonomy (Anderson \& Krathwohl, 2001). As explained in short by Krathwohl (2002), Bloom's taxonomy was one dimensional and the new proposal revised that fact and turned to two dimensions, Knowledge and Cognitive Process; establishing a hierarchy in the Cognitive Process dimension. It is within the Cognitive Processes dimension that Apply, defined as "Carrying out or using a procedure in a given situation" (p. 215) is the third level, from low to high, just above Understandsomehow implying for this interpretation that understanding is a pre-requisite for application - but well below the top level, Create. In that sense, AE requires students to combine different cognitive processes, allowing for students to undertake tasks in levels other than application, including higher cognitive processes as creation in the development of appealing ways to communicate. Also, the peer-reviewing part of the activity calls for explicit use of Analyze and Evaluate, just in case those categories were not involved in deep in the choices made for the creation of their own submission.

From the mathematics education perspective, AE fits within some features of widely accepted theoretical frameworks on building understanding, though it was not created to match any of them. Just to begin mentioning some of them, going back to Brownell (1947), the teaching for procedural fluency fits mostly with meaningless teaching, with some lights of meaning for in terms of the procedures achieveing meaning when students are able to overcome previous blockages, while the inclusión of AE provides the opportunity for the inclusión of meaning for as procedures are meaningful for their own explanation, and additional meaning of as the value of procedures and pre-requisites is highlighted in the construction of the explanation.

In the sense mentioned above, the relation of the procedures and the pre-requisites to create the explanation going beyond plain result, $\mathrm{AE}$ guides the students on crossing the line between instrumental and relational in the Skemp (1976) framework. As procedures are no longer limited by the instrumental perspective, their application needs to be seen in relation to the application of other procedures known before, and relation between concepts becomes relevant as students advance to complete the activity.

From Pirie and Kieren (1994), in their steps to build understanding, there is a quote supporting the implementation of activities involving verbalization of understanding, as AE hopes to be: "It seems that at both image having and property noticing levels the 'acting' notions are ephimeral and without the complementarity of 'expressing' do not remain with the student from one lesson to the next" (p. 180). As image having and property noticing are steps on the way for students to achieve a complete concept construction, the need of 
'expressing' is immediately supported, and this kind of activities allow for students to communicate within their small groups and later with bigger communities, for example the community of classmates via the comments in the forums.

All of these seem to also fit the Learning Pyramid framework. The learning pyramid, with origins that are not perfectly clear, is commonly attributed to the NTL Institute for Applied Behavioral Science and this attribution is accepted even by the own institute (Polovina, 2011). Adaptations of the learning pyramid have been made in different contexts and even with different values for the percentages of learning and retention, being highly relevant here the one shared by The World Bank (n.d.), placing the retention rate-and therefore the learning - of teaching at the $90 \%$, the highest of all the shown ones. Although the learning pyramid seems to lack the evidence needed to support the use of particular percentages and the implied comparison between ways to deal with the information acquired (Letrud \& Hernes, 2016) the value of teaching as a tool for learning is supported beyond the pyramid framework, as evidence in Cortese (2005), Chase, Chin, Oppezzo, and Schwartz (2009), or Nestojko, Bui, Kornell, and Bjork (2014) supports. Furthermore, there is a whole theory on learning by teaching, known as LdL for its German acronym, as presented by Grzega (2005, Sep). In mathematics, learning by teaching is common in teacher training, as presented in the book edited by Leikin and Zazkis (2010), and it is widely accepted in different contexts, as for example the highly regarded web community Art of Problem Solving (Rusczyk, 2009).

All these theoretical support for the content of the activity is accompanied by additional support on the means of the activity: autonomous selection on the way to deliver and the question to be solved are inspired on the short review of autonomy as a motivation driver by McKeachie and Svinicki (2013); technology as a motivator is inspired in Prensky (2001, October) and Handley (2014); involving creativity and hands-on work to increase motivation responds to the findings shown by Askell-Williams and Lawson (2001).

\section{Shortcommings}

Shortcommings on implementation are to be obtained through research on the outcomes, though none of said research has been done. However, there are caveats on the possible gains by students from the activity, especially taking into account the way students are tested in this kind of courses. It has to be acknowledged, for example, the general observation Nesher (1986) finds in any implementation of activities devoted to understanding beyond procedural fluency when students are to be tested on procedural fluency: "No one has succeeded in demonstrating that understanding improves algorithmic performance, though we all feel, intuitively, that this is the case, we are still ina state of wishful thinking without grounded facts" (p. 16). This means that, even if students are 
gaining in understanding and ability to create conceptual relations in mathematics, as long

as the testing is limited to procedural fluency, the students will not be able to see their effort as improved results in testing.

An expected shortcoming, already experienced during the first semester of application, though not measured, is the lack of critical reading by students when faced by an authoritative source. Finding a proposed solution for the problem online-it is possible to find solutions online to most of the course textbook exercises - and being confronted with the need to criticize and provide feedback for their peers are situations where students may see themselves as not having what is needed to question what is shown to them.

\section{Personal Reflection from the Teacher}

AE was a roller coaster of emotions during the semester. Problems in the implementation were found every week at the moment of submission, with students having trouble uploading some types of files, Blackboard limiting the size of the files they were able to upload, misunderstandings on the meaning of deadlines, failure to conceptualize the meaning of "going beyond mute slides' presentations" and other ways to present the desired outcomes, and all other kinds of small trouble requiring quick fixes.

However, conversations with students at the end of the semester brought to the light two common themes: joy in making the submissions and disappointment in receiving few to none feedback. Adding the submissions, fourteen total, to a course schedule already including four quarter-term tests and ten in-class worksheets per group, with two groups running simultaneously, was too ambitious and backfired quickly. I tried to provide feedback for every group on those submissions exposed in the forums, and students were thankful for the comments received. This idea of providing feedback via forum, as seemed successful and was supported by students' comments and theory, led to changes in the implementation for the second semester.

Students were also positive in their comments. On top of the already mentioned joy on the preparation, most of the students said it was nice to see their ideas going into practice. The possibility to explore presentation tools, including recordings of the traditional board-andmarker structure, different options and configurations in PowerPoint presentations, and web-based tools as Prezi or PowToon, was highlighted as valuable from their perspective. Also, opportunity to explore questions beyond reaching right answers, even in purely procedural questions as finding the quotient in polynomial division or adding rational expressions finding the least common denominator, showed them the value of meaningful learning and some of the conversations proved the issue to be clear for them too. 
Changes have been made, not many but some, based mainly on the conversations with students at the end of the semester (as mentioned before, for the second semester of application once again two groups of 30 students each are undertaking the modified AE). Results are expected to be reported, at least to the level of personal analysis of informal conversations with students, by late-July 2017. Research results beyond self-report analysis are not expected soon, as the number of measured variables to compare between groups and with groups not using $\mathrm{AE}$ is restricted to one (each group gets different quarter-term tests, other groups not under treatment have other teachers and different tests, the only common test comes at the end of the semester). However, self-report may turn to be a highly reliable measure for motivation, and therefore on AE's impact on climate for learning.

\section{References}

Anderson, L. W., \& Krathwohl, D. R. (Eds.). (2001). A Taxonomy for Learning, Teaching, and Assessing: A Revision of Bloom's Taxonomy of Educational Objectives. Boston, MA: Allyn \& Bacon.

Askell-Williams, H. \& Lawson, M.J. (2001). Mapping students' perceptions of interesting class lessons. Social Psychology of Education, 5(2), 127-147. doi:10.1023/A:1014415401600

Atkinson, E.S. (2000). An investigation into the relationship between teacher motivation and pupil motivation. Educational Psychology, 20(1), 45-57.

Brownell, W. A. (1947, January). The place of meaning in the teaching of arithmetic. The Elementary School Journal, 47(5), 256-265.

Chase, C. C., Chin, D. B., Oppezzo, M. A., \& Schwartz, D. L. (2009). Teachable Agents and the Protégé Effect: Increasing the Effort Towards Learning. Journal of Science Education and Technology, 18(4), 334-352.

Cortese, C. G. (2005). Learning through teaching. Management Learning, 36(1), 87-115.

Grzega, J. (2005, September). Learning By Teaching: The Didactic Model LdL in University Classes. Retrieved from http://www.joachim-grzega.de/ldl-engl.pdf

Handley, R. (2014). Digital technology and the disengaged student: Enhancing the motivation of students with behaviour needs (Doctoral dissertation). Retrieved from http://ro.uow.edu.au/theses/4190

Krathwohl, D. R. (2002). A revision of Bloom's taxonomy: An overview. Theory into practice, 41(4), 212-218.

Kuo, T., \& Simon, A. (2009). How many tests do we really need? College Teaching, 57(3), 156-160.

Leikin, R., \& Zazkis, R. (Eds.). (2010). Learning Through Teaching Mathematics. Springer. DOI: 10.1007/978-90-481-3990-3_4

Letrud, K., \& Hernes, S. (2016). The diffusion of the learning pyramid myths in academia: an exploratory study. Journal of Curriculum Studies, 48(3), 291-302. DOI: 10.1080/00220272.2015.1088063 
McKeachie, W. J., \& Svinicki, M. D. (2013). McKeachie's Teaching Tips, 14th Edition. Belmont, CA: Wadsworth - Cengage Learning.

Nesher, P. (1986, April). Are mathematical understanding and algorithmic performance related? $1-31$. Retrieved Jan 16, 2017, from http://files.eric.ed.gov/fulltext/ED275501.pdf (Paper presented at the Annual Meeting of the American Educational Research Association (67th, San Francisco, CA, April 16-20, 1986))

Nestojko, J. F., Bui, D. C., Kornell, N., \& Bjork, E. L. (2014). Expecting to teach enhances learning and organization of knowledge in free recall of text passages. Memory \& Cognition, 42(7), 1038-1048.

Pirie, S. \& Kieren, T. (1994, March). Growth in mathematical understanding: How can we characterize it and how can we represent it? Educational Studies in Mathematics, 26(2/3), 165-190.

Polovina, S. (2011, November 16). About the Learning Pyramid. Retrieved from http://homepages.gold.ac.uk/polovina/learnpyramid/about.htm

Prensky, M. (2001, October). Digital natives, digital immigrants. On the Horizon, 9(5), 1-6. doi: $10.1108 / 10748120110424816$

Rusczyk, R. (2009). Learning through teaching. Retrieved from https://artofproblemsolving.com/articles/learning-through-teaching

Ryan, R. M. \& Deci, E. L. (2000). Intrinsic and extrinsic motivations: Classic definitions and new directions. Contemporary Educational Psychology, 25, 54-67.

Simon, M. A. (1995, March). Reconstructing mathematics pedagogy from a constructivist perspective. Journal for Research in Mathematics Education, 26(2), 114-145.

Simon, M. A., \& Blume, G. W. (1994, November). Building and understanding multiplicative relationships: A study of prospective elementary teachers. Journal for Research in Mathematics Education, 25(5), 472-494.

Skemp, R. R. (1976). Relational understanding and instrumental understanding. Mathematics Teaching, 77, 20-26.

The World Bank. (n.d.). [Illustration of The Learning Pyramid]. The Learning Pyramid: Average Retention Rates. Retrieved from https://siteresources.worldbank.org/DEVMARKETPLACE/Resources/Handout_TheLe arningPyramid.pdf 